\title{
CROPGRO-Soybean Model Calibration and Assessment of Soybean Yield Responses to Climate Change
}

\section{Joseph E. Quansah1 ${ }^{*}$, Pauline Welikhe², Gamal El Afandi' ${ }^{1}$, Souleymane Fall ${ }^{1}$, Desmond Mortley ${ }^{1}$, Ramble Ankumah ${ }^{1}$}

${ }^{1}$ Department of Agricultural and Environmental Sciences, Tuskegee University, Tuskegee, AL, USA

${ }^{2}$ Agronomy Department, Purdue University, West Lafayette, IN, USA

Email: *jquansah@tuskegee.edu

How to cite this paper: Quansah, J. E., Welikhe, P., El Afandi, G., Fall, S., Mortley, D., \& Ankumah, R. (2020). CROPGROSoybean Model Calibration and Assessment of Soybean Yield Responses to Climate Change. American Journal of Climate Change, 9, 297-316.

https://doi.org/10.4236/ajcc.2020.93019

Received: July 27, 2020

Accepted: September 27, 2020

Published: September 30, 2020

Copyright $\odot 2020$ by author(s) and Scientific Research Publishing Inc. This work is licensed under the Creative Commons Attribution International License (CC BY 4.0).

http://creativecommons.org/licenses/by/4.0/

(c) (i) Open Access

\begin{abstract}
Process-based crop simulation models are useful for simulating the impacts of climate change on crop yields. Currently, estimation of spatially calibrated soil parameters for crop models can be challenging, as it requires the availability of long-term and detailed input data from several sentinel sites. The use of aggregated regional data for model calibrations has been proposed but not been employed in regional climate change studies. The study: 1) employed the use of county-level data to estimate spatial soil parameters for the calibration of CROPGRO-Soybean model and 2) used the calibrated model, assimilated with future climate data, in assessing the impacts of climate change on soybean yields. The CROPGRO-Soybean model was calibrated using major agricultural soil types, crop yield and current climate data at county level, for selected counties in Alabama for the period 1981-2010. The calibrated model simulations were acceptable with performance indicators showing Root Mean Square Error percent of between $27-43$ and Index of Agreement ranging from 0.51 to 0.76 . Projected soybean yield decreased by an average of $29 \%$ and $23 \%$ in 2045, and $19 \%$ and $43 \%$ in 2075, under Representative Concentration Pathways 4.5 and 8.5, respectively. Results showed that late-maturing soybean cultivars were most resilient to heat, while late-maturing cultivators needed optimized irrigation to maintain appropriate soil moisture to sustain soybean yields. The CROPGRO-Soybean phenological and yield simulations suggested that the negative effects of increasing temperatures could be counterbalanced by increasing rainfall, optimized irrigation, and cultivating latematuring soybean cultivars.
\end{abstract}

\section{Keywords}

Climate Change, CROPGRO-Soybean Model, Crop Yield, Soil Parameters 


\section{Introduction}

Global climate change and variability is expected to affect crop phenological processes and yield. The need for the assessment of the extent of such potential impacts have resulted in the use of several process-based crop models to simulate the unique interactions between crops, their environment (weather and soils), management practices and performance under projected future climate conditions (Ahmed \& Hassan, 2011). One commonly used process-based crop model is the Crop Growth (CROPGRO) (Jones et al., 2003). It is a grain legume model based on the SOYGRO, BEANGRO and PNUTGRO models (Tsuji et al., 1998). Numerous calibration and validation studies on CROPGRO-soybean have established the model's ability to simulate crop development and observed seed yield under different climate conditions and regions (Batchelor et al., 1993; Tsuji et al., 1998; Lal et al., 1999; Southworth et al., 2002; Wang et al., 2003; Mera et al., 2006; Res et al., 2007).

The successful use of these crop simulation models depends on the availability and use of long term experimental data for accurate calibration (Lobell \& Ortiz-Monasterio, 2006; Cabrera et al., 2007; Liu et al., 2011). However, the calibration of these models in regional climate change studies has numerous challenges. First, there is difficulty in obtaining long-term (30 or so years) data of detailed and complete regional crop growth and development information, crop yields and crop management records for use in conventional model calibration (Jiang et al., 2014). Second, soil survey reports fall short in their descriptions of soil characteristics, especially and with respect to details on physical and chemical parameters needed to approximate soil components (water, air, nutrients) and soil structure which affects root distribution (Mavromatis et al., 2001; Irmak et al., 2001).

One way to overcome these challenges is using detailed data (e.g. time-series data on phenology, growth, soil nitrogen status, etc. and/or end-of-season yield and yield-component data) obtained from sentinel sites such as agricultural experiment stations and representative farms. Through this approach, several studies have successfully assessed the impact of climate change at the regional scale. Alexandrov \& Hoogenbom (2000) calibrated and validated their CERES models for Maize and Wheat using detailed experimental data from a variety of trial sites across Bulgaria for the period 1980-1993. In their assessment of climate change and climate variability impacts on corn yields in the midwestern US, Southworth et al. (2002) used detailed experimental data for 1975-1990 obtained from two selected representative farms in Illinois to calibrate and validate CERESMaize models (Southworth et al., 2002). Brassard \& Singh (2007) used experimental data for 1961-1990 from agricultural research stations to calibrate CERES, CROPGRO and SUBSTOR models in order to study climate change impacts on crops in southern Québec, Canada.

A second approach is estimating spatially variable soil parameters in a systematic, stepwise, and subjective approach for the calibration of crop models. 
Considering that soils do not change over several decades, Mavromatis et al. (2001) and Irmak et al. (2001), employed reverse modeling in which historical yields, which had been de-trended to remove technological influences, were used to estimate select soil parameters. This was accomplished manually or through use of algorithms, systematically manipulating soil parameters until simulated model outputs mimicked historical yields, and analyzed statistics show low Root Mean Square Error (RMSE) and high Index of Agreement (d-statistic). Crop production is a significant component of Alabama's economy with soybeans being among the top five important crops in the state (USDA-NASS, 2015). Soybean serves as both source of food and feed in Alabama. The study, therefore aimed to 1) employ hindcast to subjectively estimate selected soil parameters for the CROPGRO-Soybean model based on historical yields, 2) assess the extent to which this approach allowed the models to reproduce observed yields and, 3) use the calibrated model to assess the impact of climate change on soybean yields in Alabama.

\section{Materials and Methods}

\subsection{Study Area}

The study sites include four counties within the State of Alabama in the US, which are among the highest soybean producers in the state, and whose historical yield statistics were readily available to the public. Counties were also selected to represent a spatial distribution or trends across the state to better incorporate the different weather patterns between the southern, central, and northern parts of the state. The research Counties selected are Limestone $\left(34^{\circ} 50^{\prime} \mathrm{N}, 8656^{\prime} \mathrm{W} ; 207 \mathrm{~m}\right)$, DeKalb ( $\left.34^{\circ} 31^{\prime} \mathrm{N}, 85^{\circ} 41^{\prime} \mathrm{W} ; 297 \mathrm{~m}\right)$, Dallas County $\left(32^{\circ} 13^{\prime} \mathrm{N}, 87^{\circ} 8^{\prime} \mathrm{W} ; 44 \mathrm{~m}\right)$ and Baldwin $\left(30^{\circ} 36^{\prime} \mathrm{N}, 87^{\circ} 46^{\prime} \mathrm{W} ; 44 \mathrm{~m}\right.$ ) (Figure 1).

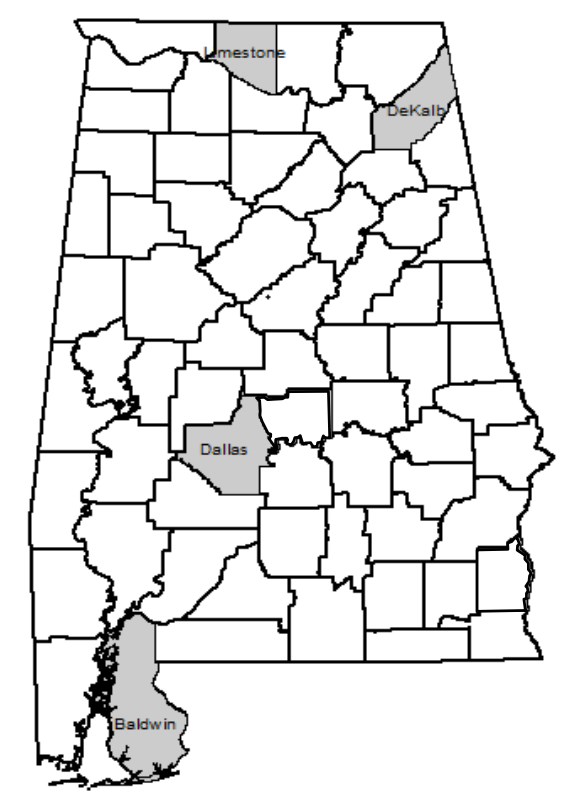

Figure 1. Location of research counties sites in Alabama, USA. 


\subsection{DSSAT Crop Simulation Model: CROPGRO-Soybean Model}

The Decision Support System for Agrotechnology Transfer (DSSAT), v4.6, is a software suit of over 28 crop simulation models (Hoogenboom et al. 2015). The software application is supported by database management programs for soil, weather, and crop management and experimental data, and by utilities and application programs in its simulations of growth, development and yield as functions of the soil-plant-atmosphere dynamics (Hoogenboom et al. 2015). In this study, CROPGRO-Soybean model was used to simulate crop growth. CROPGROSoybean model simulates growth, development and yield of a crop using prescribed or simulated management together with changes in soil water, carbon and nitrogen that take place during a cropping system.

\subsection{Crop Model Inputs}

\subsubsection{Weather Data}

Daily weather data (minimum and maximum air temperature, rainfall, solar radiation) for each site were obtained from the US Department of AgricultureAgriculture Research Service (USDA-ARS) website

(http://ars.usda.gov/Research/docs.htm?docid=19422) and National Aeronautics and Space Administration-Prediction of Worldwide Energy Resource (NASAPOWER) websites

(http://power.larc.nasa.gov/cgi-bin/cgiwrap/solar/agro.cgi?email=agroclim@larc. nasa.gov).

\subsubsection{Crop Yield Data}

Soybean observed yield data for the period 1981-2010 were obtained from US Department of Agriculture-National Agricultural Statistics Service (USDA-NASS), Alabama field Office, County Estimates (USDA-NASS, 2015). The data was collected for Limestone, De Kalb, Dallas, and Baldwin counties. County selection was based on high soybean producers, presence of agricultural research centers, availability of data and location, i.e. north, center and south of the state. During this period (1981-2010), the observed soybean yields exhibited positive yield trends (Figure 2).

These observed crop yields were de-trended/adjusted to remove technology effects using a conventional simple linear regression model [time $=$ independent predictor of yield] (McQuigg et al., 1973; Huang et al., 2015). The need for this procedure stems from the fact that technology influences positive yield trends for almost all crops in the US, including soybeans (Easterling et al., 1996; Huang et al., 2015; USDA-NASS, 2015). In this study, yields were adjusted using the linear trend shown below:

$$
Y_{i j}^{\prime}=Y_{i j}+\text { Slope of linear regression }(A-(i)) .
$$

where: $i=$ year; $j=$ county; $Y_{i j}^{\prime}=$ is the adjusted crop (soybean) yield in the county $(j)$ in year $(i) ; Y_{i j}=$ is the crop (soybean) yield for a county $(j)$ in year (i); $\mathrm{A}=$ is the year to which the yields were adjusted/de-trended (i.e., 2004). 


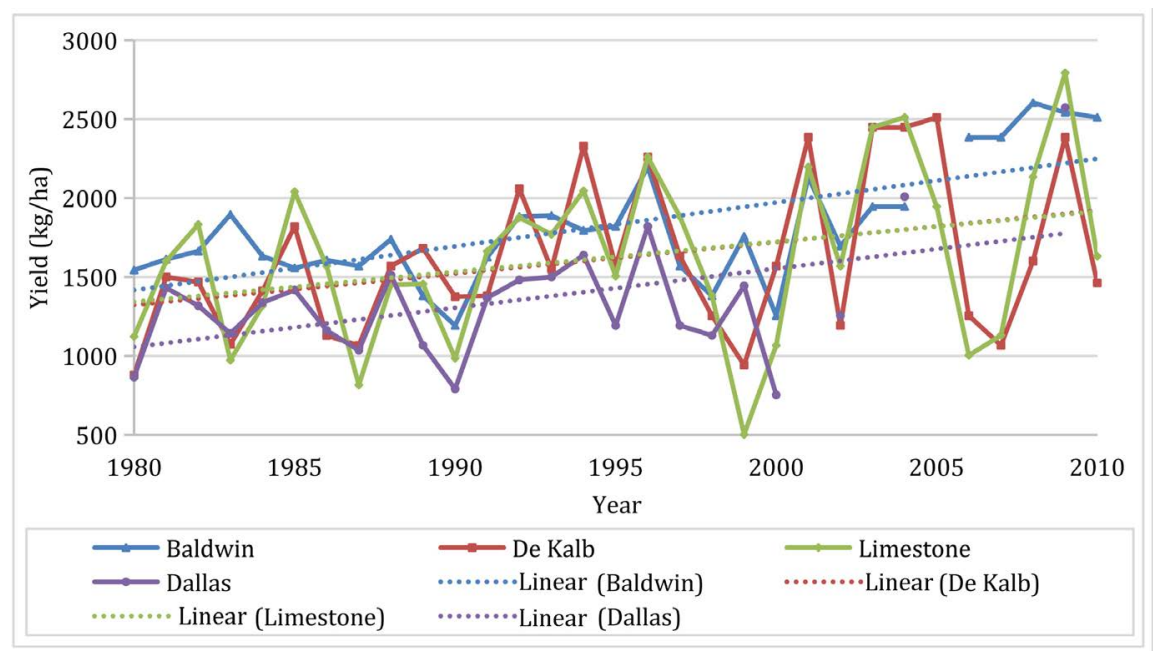

Figure 2. Annual soybean yields for selected counties in Alabama (1981-2010).

\subsubsection{Crop Management Data}

"Planting windows" were estimated from planting dates obtained from US Department of Agriculture National Agricultural Statistics Service (USDA-NASS) website (Table 1). The model was set to simulate planting when the lower limit of percentage of soil water reaches or exceeds 70 and the soil warms up sufficiently. The nitrogen application rate and depths as well as row and plant spacing, and depth used were based on recommendations by the Alabama Agricultural Experiment Stations (AAES). The study assumed irrigation and pesticide application were absent from the study sites and therefore were not considered.

\subsubsection{Cultivars and Genetic Coefficients}

The crop cultivars were characterized by a specific set of genetic coefficients the model uses to simulate and predict the daily growth and development of the plants in response to weather, soil conditions and management practices. The study employed the model's validated generic soybean coefficients for the different soybean Maturity Groups (MG) (Tsuji et al., 1994). The MG 5 was used for Limestone and De Kalb counties while MG 6 and MG 7 were used for Dallas and Baldwin counties, respectively (Table 2 ).

\subsubsection{Soil Data}

The majority soil series used for agricultural purposes were identified from USDA soil surveys and published works and used as representative soils for the study sites (Table 3).

\subsubsection{Future Climate Scenarios}

MarkSim DSSAT weather generator (http://gisweb.ciat.cgiar.org/MarkSimGCM/) was used to downscale future climate data from two General Circulation Models (GCM): MIROC 5 (Watanabe et al., 2010) and IPSL-CM5A-MR (Dufresne et al., 2013). At each study site, climate scenarios were generated for two future periods: "2045" (2030-2060), and "2075" (2060-2090). Future climatic conditions according to the Representative Concentration Pathway (RCP) 4.5 and 8.5 
Table 1. Crop planting information (obtained from AAES).

\begin{tabular}{cc}
\hline Crop Management & Soybean \\
\hline Planting window & $15^{\text {th }}$ May- $15^{\text {th }}$ June \\
Planting method & Dry seed \\
Planting distribution & Rows \\
Planting depth $(\mathrm{cm})$ & 4 \\
Plant population at seeding (plants $\left./ \mathrm{m}^{2}\right)$ & 37 \\
Plant population at emergence (plants $\left./ \mathrm{m}^{2}\right)$ & 37 \\
Row spacing $(\mathrm{cm})$ & 76.2 \\
\hline
\end{tabular}

Table 2. Generic soybean genetic coefficients (MG) (Tsuji et al., 1994).

\begin{tabular}{|c|c|c|c|c|}
\hline \multirow{2}{*}{ Coefficient } & \multirow{2}{*}{ Definition } & \multicolumn{3}{|c|}{ Value } \\
\hline & & MG 5 & MG 6 & MG 7 \\
\hline CSDL & $\begin{array}{l}\text { Critical short-day length below which reproductive } \\
\text { development progresses with no daylength effect (hour) }\end{array}$ & 12.83 & 12.58 & 12.33 \\
\hline PPSEN & $\begin{array}{l}\text { Slope of the relative response of development to photoperiod } \\
\text { with time (positive for short day plants) ( } 1 \text { /hour) }\end{array}$ & 0.30 & 0.31 & 0.32 \\
\hline EM-FL & $\begin{array}{l}\text { Time between plant emergence and flower appearance (R1) } \\
\text { (photothermal days) }\end{array}$ & 19.80 & 20.20 & 20.80 \\
\hline FL-SH & $\begin{array}{l}\text { Time between first flower and first pod (R3) } \\
\text { (photothermal days) }\end{array}$ & 8.00 & 9.00 & 10.00 \\
\hline FL-SD & $\begin{array}{l}\text { Time between first flower and first seed (R5) } \\
\text { (photothermal days) }\end{array}$ & 15.50 & 16.00 & 16.00 \\
\hline SD-PM & $\begin{array}{l}\text { Time between first seed (R5) and physiological maturity (R7) } \\
\text { (photothermal days) }\end{array}$ & 34.80 & 35.60 & 36.40 \\
\hline FL-LF & $\begin{array}{l}\text { Time between first flower(R1) and end of leaf } \\
\text { expansion (photothermal days) }\end{array}$ & 18.00 & 18.00 & 18.00 \\
\hline LFMAX & $\begin{array}{l}\text { Maximum leaf photosynthesis rate at } 30^{\circ} \mathrm{C}, 350 \mathrm{vpm} \mathrm{CO} \text {, and } \\
\text { high light }\left(\mathrm{mg} \mathrm{CO}_{2} / \mathrm{m}^{2} / \mathrm{s}\right)\end{array}$ & 1.03 & 1.03 & 1.03 \\
\hline SLAVR & $\begin{array}{l}\text { Specific leaf area of cultivar under standard growth conditions } \\
\left(\mathrm{cm}^{2} / \mathrm{g}\right)\end{array}$ & 375.00 & 375.00 & 375.00 \\
\hline SIZLF & Maximum size of full leaf (three leaflets) $\left(\mathrm{cm}^{2)}\right.$ & 180.00 & 180.00 & 180.00 \\
\hline XFRT & $\begin{array}{l}\text { Maximum fraction of daily growth that is partitioned to seed } \\
+ \text { shell }\end{array}$ & 1.00 & 1.00 & 1.00 \\
\hline WTPSD & Maximum weight per seed (g) & 0.18 & 0.18 & 0.18 \\
\hline SFDUR & $\begin{array}{l}\text { Seed filling duration for pod cohort at standard growth } \\
\text { conditions (photothermal days) }\end{array}$ & 23.00 & 23.00 & 23.00 \\
\hline SDPDV & $\begin{array}{l}\text { Average seed per pod under standard growing conditions } \\
(\# / \text { pod) }\end{array}$ & 2.05 & 2.05 & 2.05 \\
\hline PODUR & $\begin{array}{l}\text { Time required for cultivar to reach final pod load under } \\
\text { optimal conditions (photothermal days) }\end{array}$ & 10.00 & 10.00 & 10.00 \\
\hline THRSH & $\begin{array}{l}\text { Threshing percentage. The maximum ratio of seed/(seed }+ \\
\text { shell) at maturity. Causes seeds to stop growing as their dry } \\
\text { weight increases until shells are filled in a cohort. }\end{array}$ & 78.00 & 78.00 & 78.00 \\
\hline SDPRO & Fraction protein in seeds (g(protein)/g(seed)) & 0.40 & 0.40 & 0.40 \\
\hline SDLIP & Fraction oil in seeds ( $($ oil $) / g($ seed $))$ & 0.20 & 0.20 & 0.20 \\
\hline
\end{tabular}


Table 3. Representative soil series of counties and their sources.

\begin{tabular}{cclcc}
\hline County Name & Representative Soil Series & Description & Profile Information Source \\
\hline Limestone & Decatur Silty Loam & Moderate drainage, water holding capacity approx., $0.20\left(\mathrm{~cm}^{3} / \mathrm{cm}^{3}\right)$ & NRCS Soil survey \\
DeKalb & Dickson Silt Loam & Moderately well drained, water retention difference $0.12-0.23\left(\mathrm{~cm}^{3} / \mathrm{cm}^{3}\right)$ & NRCS soil survey. \\
& Canton Bend Sandy Loam & Medium in natural fertility, water holding capacity $0.11-0.18\left(\mathrm{~cm}^{3} / \mathrm{cm}^{3}\right)$ & NRCS soil survey. \\
Dallas & Low in natural fertility, moderately drained, water holding capacity of & NRCS soil survey. \\
Baldwin & Dothan Sandy Loam & $0.08-0.12\left(\mathrm{~cm}^{3} / \mathrm{cm}^{3}\right)$ & \\
& & &
\end{tabular}

respectively, for medium and high radiative forcing conditions, were used for the study. The two study periods allowed for the assessment of climate change impact in the near term ("2045”) and in the long term, (“2075”). Data were downloaded for the following future scenarios: 2045 RCP 4.5 MIROC5, 2045 RCP 8.5 MIROC5, 2075 RCP 4.5 MIROC5, and 2075 RCP 8.5 MIROC5, 2045 RCP 4.5 IPSL-CM5A-MR, 2045 RCP 8.5 IPSL-CM5A-MR, 2075 RCP 4.5 IPSLCM5A-MR, and 2075 RCP 8.5 IPSL-CM5A-MR.

\subsubsection{Carbon Dioxide Fertilization Effect-DSSAT Simulations}

Another aspect of climate change which impacts crop yields is carbon dioxide. Elevated carbon dioxide concentrations affects yields in two ways: promotion of photosynthesis and secondly through improved water use efficiency (Justino et al. 2013). To simulate the fertilization effect of $\mathrm{CO}_{2}$ on crop physiology, carbon dioxide concentration levels were introduced directly in the environmental modifications of DSSAT (Justino et al., 2013).

\subsection{Soil Parameterization}

This study employed a hindcast method to calibrate selected soil parameters using stepwise procedure adopted from Mavromatis et al. (2001). The soil parameters which defined water availability, water holding capacity, fertility and root growth were selected, and their initial values were set for at field-based measured values for Alabama region according to Ratliff et al. (1983). The purpose of this was to have a good starting point to help optimize the calibration the soil parameters. The best values of the parameters were chosen by simulating 30 years historical yields in CROPGRO-Soybean model and using scatter plots of observed, which had been adjusted to remove technology effects and simulated yields to evaluate the performance of the models. The set of parameters that gave the highest d-statistic and the lowest RMSE was then chosen. To further assess the accuracy of the CROPGRO-Soybean model calibration and statistics, the study employed scatter plots to evaluate model simulations and measured data (Liu et al., 2011). The scatter plots of observed versus simulated yields allows the modeler to examine how the manual shifts of the different soil parameters affect yield simulations.

The initial soil profile conditions used before the calibration process started were based on default model variables values and values reported by Ratliff et al. 
(1983), which were set to start on January 3 of each year, a day before the start of simulations. For each soil within the study sites, the Soil Drained Upper Limit (SDUL), Soil Lower Limit (SLL) of extraction, Upper Limit Saturated (SAT), Soil Fertility Factor (SLPF) and the Soil Root Growth Factor (SRGF) were parameterized. For each of the soils, the delta (difference between drained upper limit (DUL) and lower limit (LL)) for each of the layers in the profile was initially set to a similar starting point: $0.100 \mathrm{~cm}^{3} / \mathrm{cm}^{3}$. The delta was shifted by adding or subtracting $0.005 \mathrm{~cm}^{3} / \mathrm{cm}^{3}$ to either the LL or DUL while checking the lower end of the scatter plots to see how well the simulated yields mimicked the observed yields in the water limited years of the baseline. Once shifts in the delta stopped improving model performance, attention was turned to the SAT values. The SAT values were then successively shifted by $\pm 1 \mathrm{~cm}^{3} / \mathrm{cm}^{3}$ while checking how simulated yield mimicked the observed yields in the scatter plots in the water-limited years. This study ensured that the SAT values were always greater than the DUL values as pointed out by Romero et al. (2012). It is worth noting that the initial SAT value of the top layer was adopted in all the successive layers before systematic shifts were made. SLPF (scale of 0 - 1) for each of the soils was initially set to 1.00 to give a similar starting point and then shifted by \pm 0.01 while checking the higher end of the 1:1 scatter plots to see how well the simulated yields mimicked the observed yields in the good (high) yielding years in the baseline. After the optimization was complete, the SRGF was set to 1 in the layers whose center was $\leq 30 \mathrm{~cm}$ from the top of the surface layer. The initial starting point SRGF for the remaining layers beneath was estimated using the relationship established by Gijsman et al. (2007), and given as $1 \times$ exponential ( -0.02 LayerCentre) i.e. depth from the top of the soil surface to the center of the layer of interest.

\subsection{Climate Change Impact Assessment}

To assess the response of soybeans to future climate scenarios, the study utilized the seasonal analysis program of DSSAT v4.6 whereby seasonal experiments were set up, model simulations were run, and finally biophysical analysis of model results was done. The crop management variables, genetic coefficients and optimized soil profiles from current climate simulations were taken as input data during the assessment. In addition to the current weather data, future climate scenarios obtained from MarkSim were included in the analysis. Comparisons were made between mean yields of the baseline and future climate scenarios, with and without carbon fertilization. To assess the effect of carbon fertilization on soybean, carbon dioxide concentration was changed in the environmental modifications section of DSSAT v4.6 in each of the future climatologies treatments, as shown in Table 4.

\section{Results}

\subsection{Adjusted Yields}

The de-trending/adjustments of soybean yields resulted in trend line gradients 
Table 4. Carbon dioxide additions to the environmental modifications section of DSSAT.

\begin{tabular}{cc}
\hline Treatment Name & Carbon dioxide additions \\
\hline 2075 IPSL-CM5A-MR RCP 4.5 & $140 \mathrm{ppm}$ \\
2075 MIROC 5 RCP 4.5 & $140 \mathrm{ppm}$ \\
2075 IPSL-CM5A-MR RCP 8.5 & $272 \mathrm{ppm}$ \\
2075 MIROC 5 RCP 8.5 & $272 \mathrm{ppm}$ \\
\hline
\end{tabular}

close to zero for all counties (Figure 3). The remaining residuals in the graphs indicate the inter-annual variations in yields due to weather (Easterling et al., 1996; Osborne \& Wheeler, 2013; Huang et al., 2015). The adjustment resulted in soybean yields decreases to attain a period of approximately constant technology.

\subsection{Model Calibration and Estimated Soil Parameters}

The Soil Fertility Factor (SLPF) values ranged from 0.572 to 0.758 (Table 5), which is within the range of values supported in the literature (Irmak et al., 2001; Mavromatis et al., 2001). Delta (DUL-LL) ranged from $0.085 \mathrm{~cm}^{3} / \mathrm{cm}^{3}$ to 0.220 $\mathrm{cm}^{3} / \mathrm{cm}^{3}$ for the soil profile layers for the different county sites (Table 5). The final saturation point/volumetric soil water content (SAT) values ranged between $0.449 \mathrm{~cm}^{3} / \mathrm{cm}^{3}$ and $0.690 \mathrm{~cm}^{3} / \mathrm{cm}^{3}$ (Table 5). These increases in delta (DUL-LL) and SAT were done with reduction in SLPF that led to low RMSE percentages and greater than $0.5 \mathrm{~d}$-statistic.

In all the sites, Soil Root Growth Factor (SRGF) varied throughout the layers (Table 6). The slightly high RMSE percentage indicated an uncertainty in soybean annual yield simulations, possibly associated with biotic stresses that the model does not simulate (disease, insects, etc.). These uncertainties are reflections of factors and events that are not considered in the model (Liu et al., 2011). The final calibrated SDUL and SLL values were within the ranges for texture and water retention data results by Fatliff et al. (1983). The use of generic DSSAT soybean genetic coefficients in this study together with the other assumptions may have contributed to the higher uncertainties.

Model R square values was ignored during the assessment of model performance because the study used time series data (30-year historic yields) which are auto-correlated values. To overcome this, correlation-based statistics (d-statistic and RMSE efficiency measures) were used to assess model performance. The yield simulations closely mimicked observed yields for the De Kalb and Dallas Counties while for Limestone and Baldwin counties the model slightly overestimated during the high yielding years and underestimated for low yielding years. The greater than $0.5 \mathrm{~d}$-statistic, indicate that the CROPGRO-Soybean model yield simulations were in good agreement with observed yields.

\subsection{Changes in Projected Climate Variables}

To assess the changes in projected climate variables, the baseline period (1981-2010) representing current climatic conditions was used as a reference for comparison 
Table 5. CROPGRO-soybean model Calibrated SLPF values and statistics for research counties.

\begin{tabular}{cccccc}
\hline \multirow{2}{*}{ County } & Soil Series & Soil Parameters & \multicolumn{3}{c}{ CROPGRO Model Statistics } \\
\cline { 3 - 6 } & SLPF $(0-1)$ & $\begin{array}{c}\text { “Delta" } \\
\left(\mathrm{cm}^{3} / \mathrm{cm}^{3}\right)\end{array}$ & $\begin{array}{c}\text { RMSE } \\
(\%)\end{array}$ & d-Statistic \\
\hline Baldwin & Dothan sandy loam & 0.700 & 0.085 & 29 & 0.572 \\
De Kalb & Dickson silt loam & 0.650 & 0.155 & 31 & 0.705 \\
Limestone & Decatur silt loam & 0.700 & 0.220 & 43 & 0.758 \\
Dallas & Canton Bend Sandy Loam & 0.570 & 0.201 & 27 & 0.506 \\
\hline
\end{tabular}

Table 6. CROPGRO-Soybean model calibrated soil parameters for research Counties. (a) Baldwin County Site-TU00000012; (b) Dallas County Site-TU00000014e; (c) De Kalb County Site-TU00000013; (d) Limestone County Site-TU00000011.

(a)

\begin{tabular}{cccccc}
\hline & Dothan Sandy Loam & & \multicolumn{3}{c}{ SLPF: 0.70 } \\
\hline Layer & Depth $(\mathrm{cm})$ & SLL & SDUL & SSAT & SRGF \\
\hline A & 15 & 0.068 & 0.153 & 0.449 & 1.000 \\
E & 30 & 0.046 & 0.131 & 0.449 & 1.000 \\
Bt1 & 97 & 0.116 & 0.201 & 0.449 & 0.379 \\
Bt2 & 152 & 0.169 & 0.254 & 0.449 & 0.219 \\
Bt3 & 183 & 0.296 & 0.381 & 0.449 & 0.160 \\
\hline
\end{tabular}

(b)

\begin{tabular}{cccccc}
\hline \multicolumn{3}{c}{ Canton Bend Sandy Loam } & & SLPF: 0.57 \\
\hline Layer & Depth $(\mathrm{cm})$ & SLL & SDUL & SSAT & SRGF \\
\hline Ap & 7 & 0.050 & 0.251 & 0.480 & 1.000 \\
B21t & 18 & 0.188 & 0.389 & 0.480 & 1.000 \\
B22t & 33 & 0.201 & 0.402 & 0.480 & 1.000 \\
B23t & 52 & 0.153 & 0.354 & 0.480 & 0.594 \\
B3 & 62 & 0.126 & 0.327 & 0.480 & 0.538 \\
B4 & 120 & 0.101 & 0.302 & 0.480 & 0.301 \\
B5 & 160 & 0.101 & 0.302 & 0.480 & 0.202 \\
\hline
\end{tabular}

(c)

\begin{tabular}{cccccc}
\hline & Dickson Silt Loam & & \multicolumn{3}{c}{ SLPF: 0.65} \\
\hline Layer & Depth $(\mathrm{cm})$ & SLL & SDUL & SSAT & SRGF \\
\hline Ap & 25 & 0.082 & 0.237 & 0.690 & 1.000 \\
Bw & 51 & 0.095 & 0.249 & 0.690 & 1.000 \\
Btx & 91 & 0.115 & 0.270 & 0.690 & 0.403 \\
$2 \mathrm{Btx}$ & 122 & 0.112 & 0.267 & 0.690 & 0.295 \\
$2 \mathrm{Bt}$ & 127 & 0.131 & 0.286 & 0.690 & 0.280 \\
\hline
\end{tabular}


(d)

\begin{tabular}{cccccc}
\hline & Decatur Silt Loam & & \multicolumn{3}{c}{ SLPF: 0.70 } \\
\hline Layer & Depth $(\mathrm{cm})$ & SLL & SDUL & SSAT & SRGF \\
\hline Ap & 10 & 0.113 & 0.333 & 0.519 & 1.000 \\
Bt1 & 40 & 0.180 & 0.400 & 0.519 & 1.000 \\
Bt2 & 100 & 0.235 & 0.455 & 0.519 & 0.368 \\
Bt3 & 200 & 0.240 & 0.460 & 0.519 & 0.135 \\
\hline
\end{tabular}

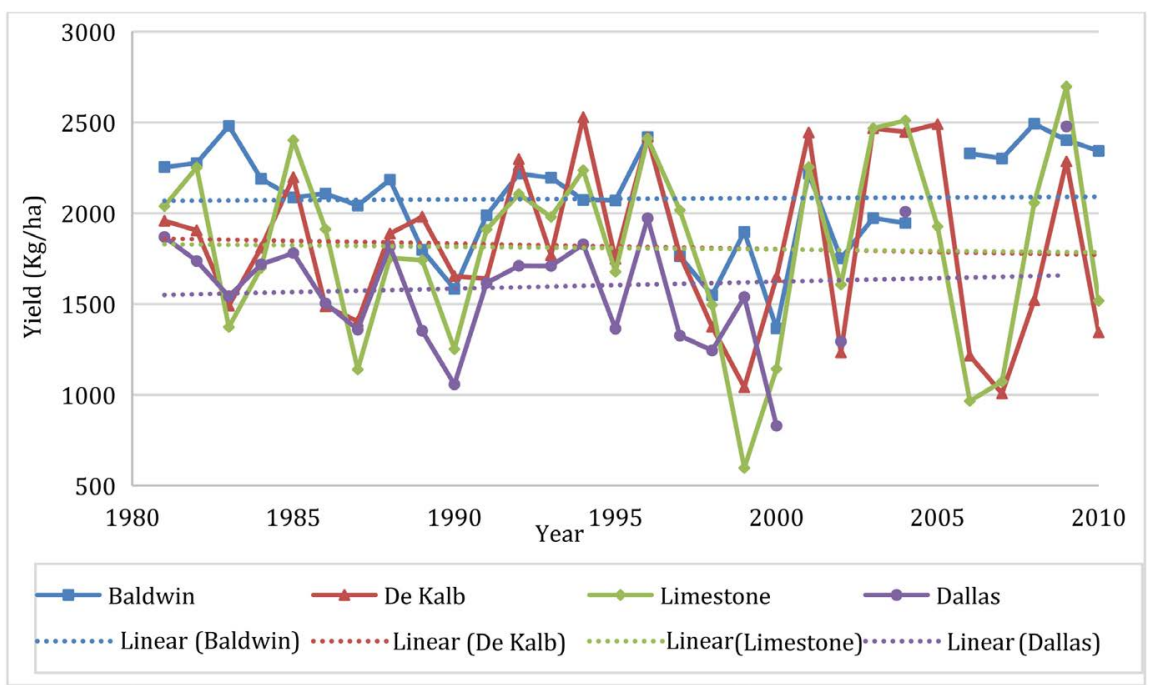

Figure 3. Adjusted county soybean yields (adjusted relative to the year 2004).

for all four selected counties (Table 7). The future annual average maximum and minimum temperatures and precipitation for the eight (8) IPSL-CM5A-MR and MIROC 5 scenarios were analyzed: 2045 RCP 4.5, 2045 RCP 8.5, 2075 RCP 4.5 and 2075 RCP 8.5.

All four sites were projected to experience increases in both maximum and minimum average annual temperatures between $1^{\circ} \mathrm{C}$ to $4^{\circ} \mathrm{C}$ depending on site, scenario, and year. However, the trend of change in projected rainfall patterns is not uniform for all study sites. Rainfall for Limestone and De Kalb Counties is projected to increase in the future scenarios in different amounts. Dallas County is projected to experience the highest rainfall increase in 2045 RCP 4.5 of 196 $\mathrm{mm}$ (MIROC 5) and $117 \mathrm{~mm}$ (IPSL-CM5A-MR). Rainfall for Baldwin County is projected to decrease under the extreme scenarios. Climate projections by MIROC 5 appear to be less extreme when compared to projections from IPSL-CM5AMR.

\subsection{Climate Change Impact Assessment}

Simulation results reflect the yield responses of the three maturity groups (MG5, MG6 and MG7) to the different projected climate scenarios and different county soils. The MG5 yields were simulated for both De Kalb and Limestone Counties while MG6 and MG7 maturity groups were simulated for Dallas and Baldwin 
Table 7. Annual average rainfall, maximum and minimum temperatures [Tmax \& Tmin] for current and projected climate scenarios at each study site.

\begin{tabular}{|c|c|c|c|c|}
\hline \multirow{2}{*}{ Climatic Variables } & \multicolumn{4}{|c|}{ County } \\
\hline & Limestone & De Kalb & Dallas & Baldwin \\
\hline \multicolumn{5}{|l|}{ Rainfall (mm) } \\
\hline Current Rainfall & 1441 & 1401 & 1371 & 1620 \\
\hline 2045 RCP 4.5-M & 1464 & 1452 & 1567 & 1603 \\
\hline 2045 RCP 4.5-I & 1448 & 1438 & 1488 & 1600 \\
\hline 2045 RCP 8.5-M & 1491 & 1448 & 1384 & 1581 \\
\hline 2045 RCP 8.5-I & 1468 & 1430 & 1256 & 1577 \\
\hline 2075 RCP 4.5-M & 1453 & 1431 & 1340 & 1567 \\
\hline 2075 RCP 4.5-I & 1453 & 1426 & 1261 & 1580 \\
\hline 2075 RCP 8.5-M & 1524 & 1427 & 1324 & 1564 \\
\hline 2075 RCP 8.5-I & 1487 & 1419 & 1164 & 1491 \\
\hline \multicolumn{5}{|c|}{ Maximum Temperature $\left({ }^{\circ} \mathrm{C}\right)$} \\
\hline Current Tmax & 22 & 21 & 24 & 25 \\
\hline 2045 RCP 4.5-M & 24 & 24 & 26 & 27 \\
\hline 2045 RCP 4.5-I & 25 & 23 & 26 & 28 \\
\hline 2045 RCP 8.5-M & 25 & 24 & 26 & 27 \\
\hline 2045 RCP 8.5-I & 25 & 23 & 27 & 28 \\
\hline 2075 RCP 4.5-M & 25 & 24 & 27 & 28 \\
\hline 2075 RCP 4.5-I & 25 & 25 & 27 & 28 \\
\hline 2075 RCP 8.5-M & 26 & 26 & 28 & 29 \\
\hline 2075 RCP 8.5-I & 27 & 26 & 29 & 29 \\
\hline \multicolumn{5}{|c|}{ Minimum Temperature $\left({ }^{\circ} \mathrm{C}\right)$} \\
\hline Current Tmin & 9 & 8 & 11 & 14 \\
\hline 2045 RCP 4.5-M & 11 & 10 & 13 & 16 \\
\hline 2045 RCP 4.5-I & 11 & 10 & 14 & 16 \\
\hline 2045 RCP 8.5-M & 11 & 10 & 13 & 16 \\
\hline 2045 RCP 8.5-I & 11 & 10 & 14 & 16 \\
\hline 2075 RCP 4.5-M & 11 & 10 & 14 & 16 \\
\hline 2075 RCP 4.5-I & 12 & 10 & 14 & 16 \\
\hline 2075 RCP 8.5-M & 12 & 12 & 15 & 17 \\
\hline 2075 RCP 8.5-I & 14 & 13 & 16 & 18 \\
\hline
\end{tabular}

I = IPSL-CM5A-MR; M = MIROC 5.

Counties, respectively. Rain-fed production without $\mathrm{CO}_{2}$ for the years 2045 and 2075 was first analyzed followed by an analysis of rain fed production with $\mathrm{CO}_{2}$ fertilization for the year 2075 when carbon dioxide concentration was projected to exceed ambient concentrations by $100 \mathrm{ppm}$. Percent changes in projected av- 
erage future soybean yields in comparison to current baseline average yields are shown in Figure 4 and Figure 5. The simulations for the year 2045 show soybean yield decreases in all counties for both climate scenarios (Figure 4). Projected yields decreased between $6 \%$ to $64 \%$ and between $4 \%$ to $41 \%$ for 2045 RCP 4.5 and RCP 8.5 respectively.

The simulations for the year 2075 show soybean yield decrease over all the counties in both climate scenarios (Figure 5). Yields is projected to decrease between $5 \%$ to $43 \%$ in RCP 4.5 and between $16 \%$ to $64 \%$ in RCP 8.5 .

When $\mathrm{CO}_{2}$ fertilization was introduced into the IPSL-CM5A-MR scenario soybean yield simulations of 2075 , the decreases were lower compared to the simulations without $\mathrm{CO}_{2}$ (Figure 6). These decreases ranged approximately $12 \%$ to $19 \%$ lower in the medium emission scenarios (RCP 4.5 ) and between $8 \%$ to $18 \%$ lower in the high emission scenarios (RCP 8.5) when compared to simulations without $\mathrm{CO}_{2}$ fertilization. The $\mathrm{CO}_{2}$ fertilization led to yield increases of $10 \%$ in Limestone County in the medium emission scenario. Overall, the $\mathrm{CO}_{2}$

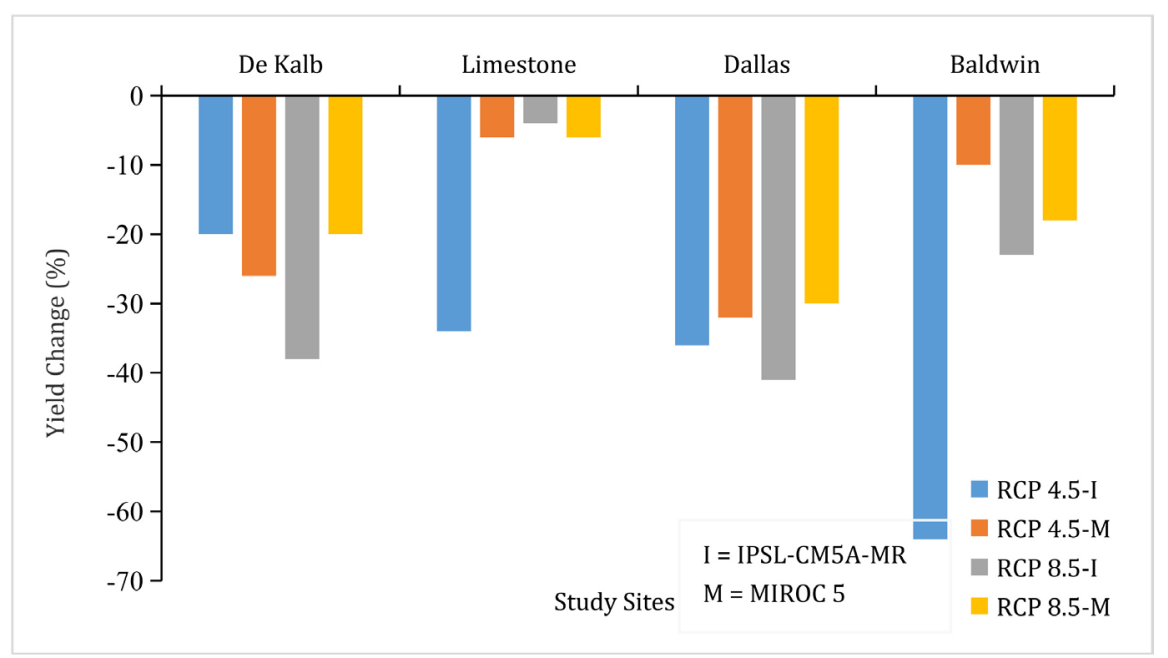

Figure 4. Projected soybean yield changes (2045).

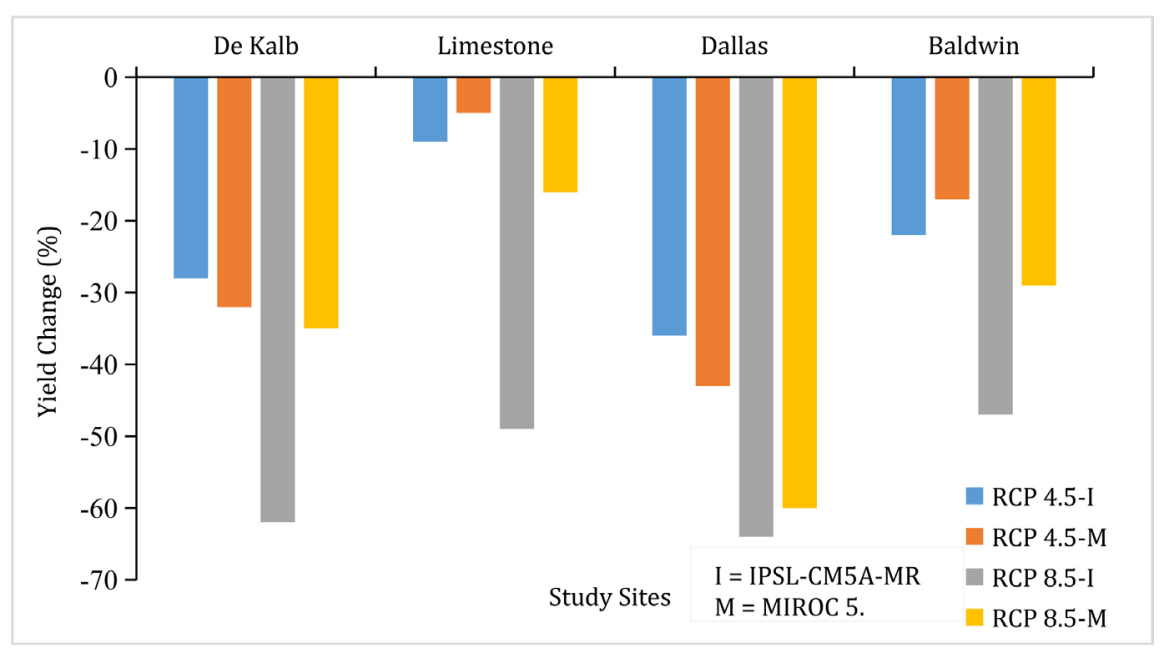

Figure 5. Projected soybean yield changes (2075). 


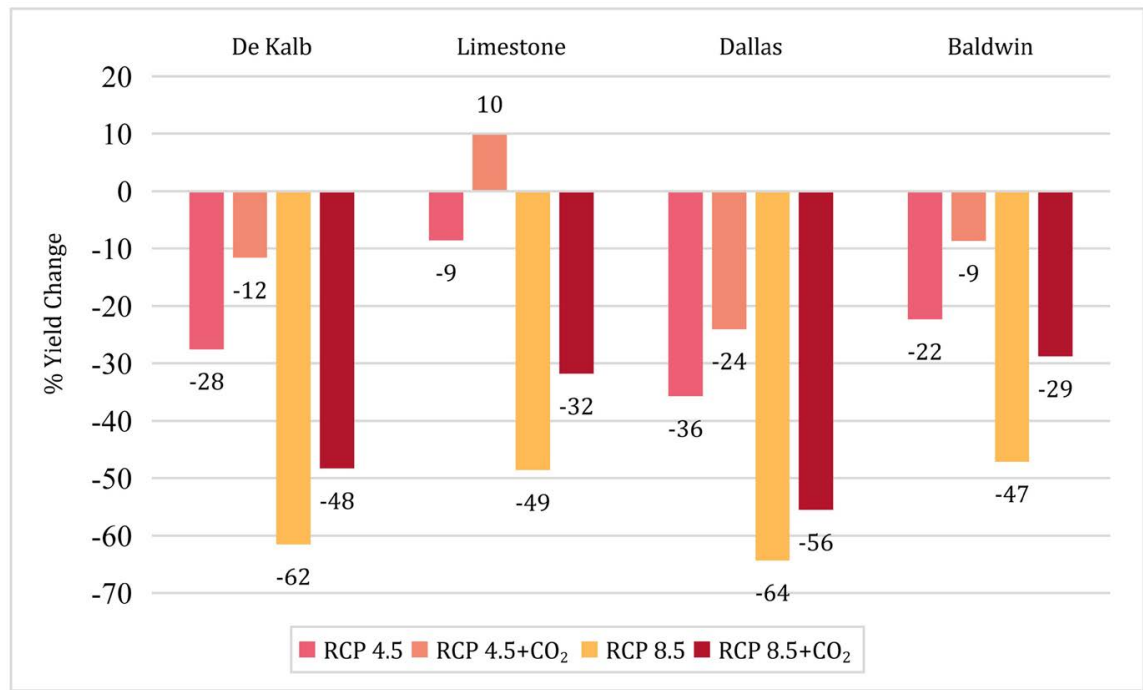

Figure 6. IPSL-CM5A-MR scenario projections of soybean yield changes for 2075. Projections are with and without carbon dioxide fertilization.

fertilization effect resulted in projected average yield decreases of between $9 \%$ to $41 \%$ under RCP 4.5 and RCP 8.5 respectively.

When $\mathrm{CO}_{2}$ fertilization was introduced into the MIROC 5 scenario soybean yield simulations of 2075, the decreases were also lower compared to the simulations without $\mathrm{CO}_{2}$ (Figure 7). These decreases were approximately $15 \%-23 \%$ lower in the medium emission scenarios (RCP 4.5 ) and $22 \%-32 \%$ lower in the high emission scenarios (RCP 8.5) when compared to the "without $\mathrm{CO}_{2}$ fertilization" simulations.

The $\mathrm{CO}_{2}$ fertilization led to yield increases of $14 \%$ and $12 \%$ in Limestone County in RCP 4.5 and RCP 8.5 respectively. Overall, the $\mathrm{CO}_{2}$ fertilization effect resulted in projected average yield decreases of $7 \%$ and $9 \%$ under RCP 4.5 (medium emissions) and RCP 8.5 (high emissions) respectively for the time period 2075 (2060-2090). In Limestone County, carbon dioxide fertilization effect was high enough to compensate negative effects of climate change resulting to projected yield increases of $14 \%$ and $12 \%$ in the medium and high emission scenarios, respectively. These results are in agreement with other studies which show that increasing atmospheric $\mathrm{CO}_{2}$ could have a compensation effect on yield decreases (Southworth et al., 2002; Res, Brassard, \& Singh, 2007).

\section{Discussion}

The research results highlight the unique response of soybeans to increasing temperatures and the model's ability to capture these responses (Tsuji et al., 1998). In soybeans, the vegetative and reproductive stages co-exist for some period of the crop life cycle with their vegetative growing periods lengthening once temperatures exceed their optimum i.e. $22^{\circ} \mathrm{C}-28^{\circ} \mathrm{C}$ (Boote, 2011) and the crop is exposed to these temperatures continuously (Setiyono et al., 2007). Observations from field experiments, showed that this temperature-induced lengthening 


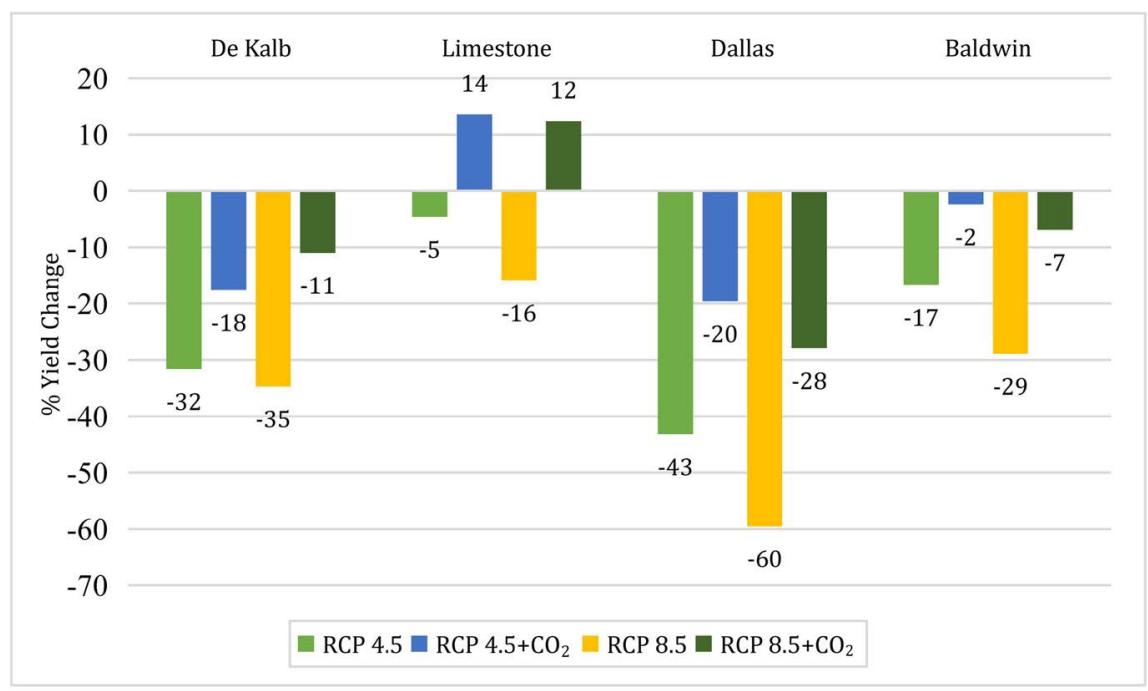

Figure 7. MIROC 5 scenario projections of soybean yield changes for 2075. Projections are with and without carbon dioxide fertilization.

of the life cycle leads to an improvement in sources (Kumagai \& Sameshima, 2014), i.e. increase in leaf area and leaf photosynthesis which contributes to an increase in photosynthesis and assimilate partitioning which results in increased yields. However, Thuzar et al. (2010) showed that the same increase in temperature that prolongs and enhances soybean vegetative growth and development also depresses reproductive growth leading to a decrease in the number of seeds produced. Findings by Setiyono et al. (2007) showed that reproductive growth would only be depressed if increased temperatures are experienced during flowering as there was no correlation between mean temperature and post flowering duration. The response of the different developmental stages to temperature and the influence of the timing when increased temperatures are experienced all combine to explain the inconsistent response in the medium and high emission scenarios of the soybean maturity groups simulated in Limestone and Baldwin counties. Additionally, cultivar specific day-length requirements influence the manner in which different maturity groups of soybeans respond to increasing temperatures (Kumagai \& Sameshima, 2014). Boote (2011) highlighted this relationship when he showed that for early maturing groups, increasing temperatures would lead to a shorter vegetative growth period, smaller leaf area, earlier flowering and pod set and eventual decreased yields. Additionally, his simulations showed that yield reductions by increasing temperatures would be smaller in late-maturing soybean groups (higher maturity groups and higher day length sensitive groups), creating an impression that late-maturing soybean cultivars would benefit from projected future temperature increases. This explains why MG7 simulated in Baldwin County on soils with poor water holding capacity still showed resilience under climate change.

The CROPGRO-Soybean model's soybean phenological simulations show how increased temperatures in future climate scenarios affected both the time of anthesis (and subsequent seed formation) and the time to maturity (Figure 8 and 
Figure 9). Both shortening and lengthening of the growth stages were experienced depending on whether the temperatures exceeded the optimum soybean temperatures $\left(22^{\circ} \mathrm{C}-28^{\circ} \mathrm{C}\right)$. The anthesis period was lengthened by 1 to 6 days depending on site location, GCM, RCP scenario and simulation year. The shortened development stages resulted in shortened life cycle, which means that crops will have less time to make use of available resources resulting in decreased yields. Similar studies found that hastened maturity and shortened life cycles contribute to decrease in yields (Tubiello et al., 2002; Southworth et al., 2000; Wang et al., 2011). Lengthening of the development stages, especially the time to anthesis, contributes to increase in yields or less yield decreases observed. As the vegetative and reproductive stages co-exist, the overall time to maturity was not greatly changed.

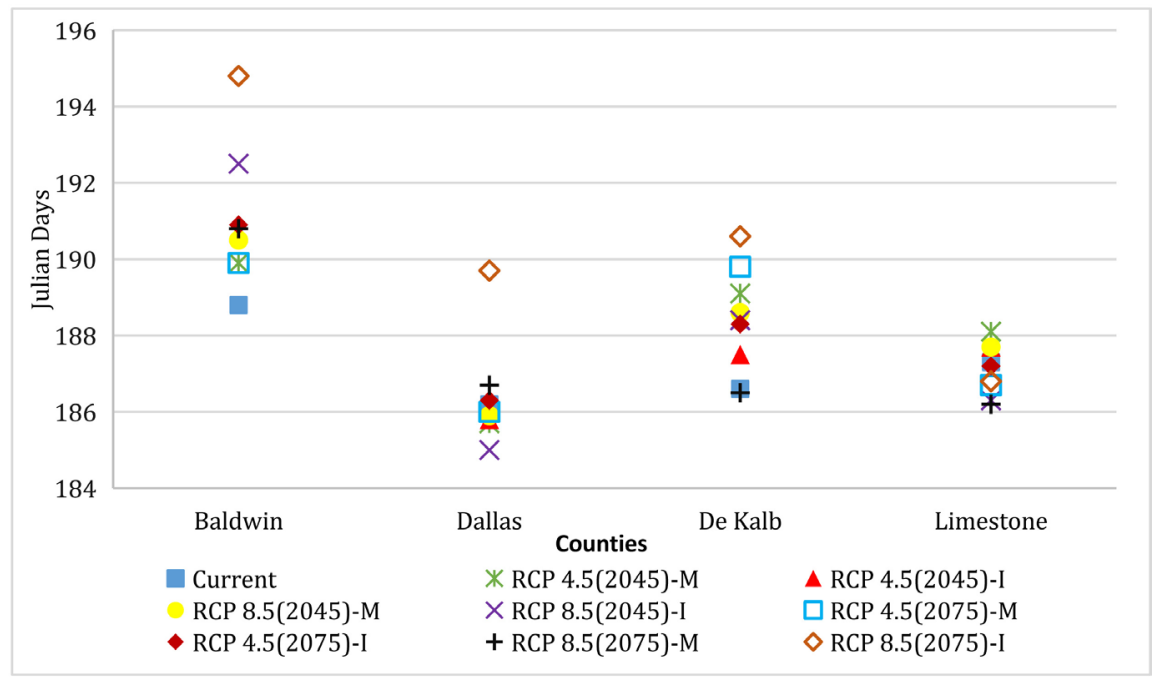

Figure 8. Soybean anthesis dates based on MIROC 5 (M) and IPSL-CM5A-MR (I) scenario simulations.

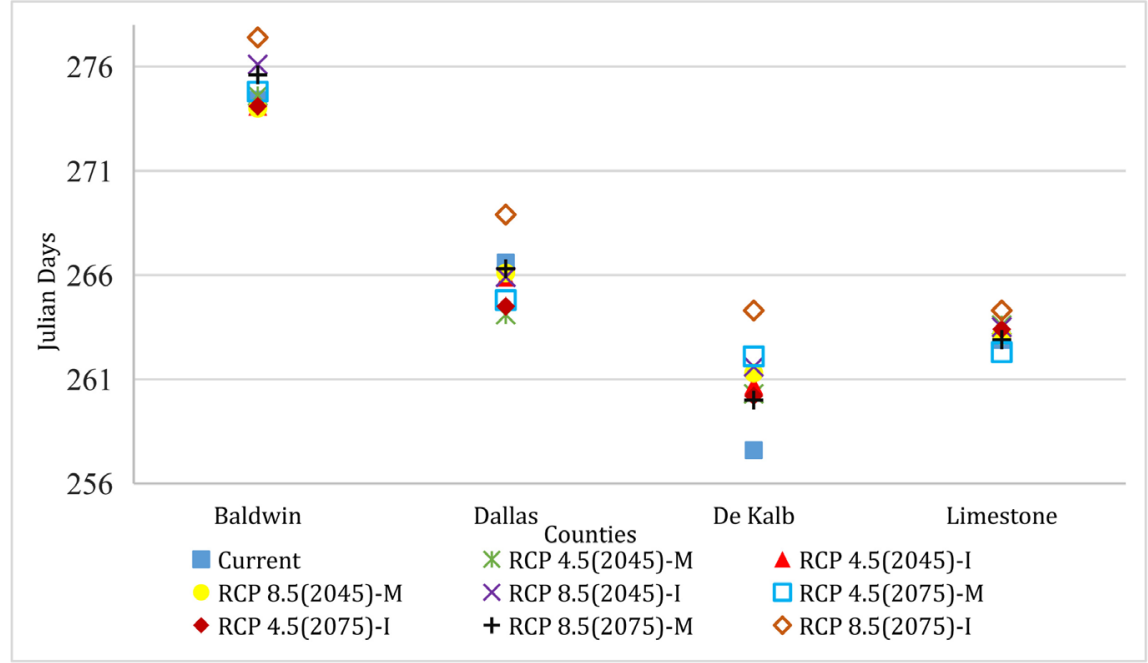

Figure 9. Soybean maturity date based on MIROC 5 (M) and IPSL-CM5A-MR (I) scenario simulations. 
The CROPGRO-Soybean model simulations revealed the different inter- and intra-specific responses of different soybean maturity groups to climate change. MG5 simulated in Limestone County with Decatur silt loam, a soil with a high water holding capacity, showed less vulnerability to climate change, while MG7 simulated in Baldwin County with Dothan sandy loam, a soil with a low water holding capacity, also showed resilience to climate change as it is a late maturing cultivar.

This study employed a stepwise hindcast method to estimate spatially variable soil parameters in calibrating the CROPGRO-Soybean model. The model was run to assess its performance with different combinations of soil parameters and a 1:1 scatter plot was used to determine and select the set of parameters that gave the highest d-statistic and lowest Root Mean Square Error (RMSE). The study found that estimating soil parameters using aggregated regional data (in this casecounty level data) resulted in calibrated model simulations that satisfactorily mimicked long-term regional yields under current climate conditions, thus ensuring reliability in regional climate change studies. This method was practical for calibrating crop models to historical yields using aggregated regional data sets.

The calibrated crop models showed that climate change will adversely affect soybean production under both medium (RCP 4.5) and high (RCP 8.5) radiative forcing conditions used in the study. Soybean yield was projected to decrease by an average of $29 \%$ and $23 \%$ in 2045 , and $19 \%$ and $43 \%$ in 2075 , under RCP 4.5 and RCP 8.5, respectively. The projected decreases were lower in MIROC 5 scenarios compared to IPSL-CM5A-MR scenarios, which had extreme projections of increase in temperature and decrease in rainfall. Considering current ongoing global efforts to mitigate climate change, the study concludes that realistic climate change impacts on soybean yields in Alabama would more likely to be within projections obtained under RCP 4.5 scenarios. Phenological simulations show that yield decreases were mainly caused by shortening crop life cycles. However, certain factors counteracted the impact of shortened life cycles on crop yields. Factors such as soil water holding capacity, soybean maturity group, timing of above optimum temperatures and water availability during the growing season, influence the crop response to climate change. The overall negative yield projection is a clear call for the development of adaptation strategies and policies to sustain current crop yields. This may involve the adaptation of new maturity groups, and development of improved cultivars, which are heat tolerant.

\section{Acknowledgements}

The study was supported by the United States Department of Agriculture (USDA) NIFA/Evans Allen under Grant [numbers 1001194]; and the National Geospatial Intelligence Agency (NGA) NARP-STEM under Grant [number U-005-15-OCSC].

\section{Conflicts of Interest}

The authors declare no conflicts of interest regarding the publication of this paper. 


\section{References}

Ahmed, M., \& Hassan, F. (2011). APSIM and DSSAT Models as Decision Support Tools. In 19th International Congress on Modelling and Simulation (pp. 1174-1180). Perth, 12-16 December 2011.

Alexandrov, V., \& Hoogenboom, G. (2000). The Impact of Climate Variability and Change on Crop Yield in Bulgaria. Agricultural and Forest Meteorology, 104, 315-327. https://doi.org/10.1016/S0168-1923(00)00166-0

Batchelor, W. D., Jones, J. W., Boote, K. J., \& Pinnschmidt, H. O. (1993). Extending the Use of Crop Models to Study Pest Damage. Transaction of the ASAE, 36, 551-558. https://doi.org/10.13031/2013.28372

Boote, K. J. (2011). Improving Soybean Cultivars for Adaptation to Climate Change and Climate Variability. In S. S. Yadav, R. J. Redden, J. L. Hatfield, H. Lotze-Campen, \& E. A. Hall (Eds.), Crop Adaptation to Climate Change (pp. 370-395). West Sussex: John Wiley \& Sons, Ltd. https://doi.org/10.1002/9780470960929.ch26

Brassard, J. P., \& Singh, B. (2007). Effects of Climate Change and $\mathrm{CO}_{2}$ Increase on Potential Agricultural Production in Southern Québec, Canada. Climate Research, 34, 105-117. https://doi.org/10.3354/cr034105

Cabrera, V. E., Jagtap, S. S., \& Hildebrand, P. E. (2007). Strategies to Limit (Minimize) Nitrogen Leaching on Dairy Farms Driven by Seasonal Climate Forecasts. Agriculture, Ecosystems \& Environment, 122, 479-489. https://doi.org/10.1016/j.agee.2007.03.005

Dufresne, J.-L., Foujols, M. A., Denvil, S., Caubel, A., Marti, O., Aumont, O., Vuichard, N. et al. (2013). Climate Change Projections Using the IPSL-CM5 Earth System Model: from CMIP3 to CMIP5. Climate Dynamics, 40, 2123-2165. https://doi.org/10.1007/s00382-012-1636-1

Easterling, W. E., Chenl, X., Haysl, C., \& James, R. (1996). Yield Response to Climate Change: An Application to the EPIC Model. Climate Research, 6, 263-273.

https://doi.org/10.3354/cr006263

Gijsman, A. J., Thornton, P. K., \& Hoogenboom, G. (2007). Using the WISE Database to Parameterize Soil Inputs for Crop Simulation Models. Computers and Electronics in Agriculture, 56, 85-100. https://doi.org/10.1016/j.compag.2007.01.001

Huang, C., Duiker, S., Deng, L., Fang, C., \& Zeng, W. (2015). Influence of Precipitation on Maize Yield in the Eastern United States. Sustainability, 7, 5996-6010. https://doi.org/10.3390/su7055996

Irmak, A., Jones, J. W., Batchelor, W. D., \& Paz, J. O. (2001). Estimating Spatially Variable Soil Properties for Application of Crop Models in Precision Farming. Transactions of the ASAE, 44, 1343-1353. https://doi.org/10.13031/2013.6424

Jiang, Z., Chen, Z., Chen, J., Liu, J., Ren, J., Li, Z., Li, H. et al. (2014). Application of Crop Model Data Assimilation with a Particle Filter for Estimating Regional Winter Wheat Yields. IEEE Journal of Selected Topics in Applied Earth Observations and Remote Sensing, 7, 4422-4431. https://doi.org/10.1109/JSTARS.2014.2316012

Jones, J. W., Hoogenboom, G., Porter, C. H., Boote, K. J., Batchelor, W. D., Hunt, L. A., Wilkens, P. W., Singh, U., Gijsman, A. J. et al. (2003). DSSAT Cropping System Model. European Journal of Agronomy, 18, 235-265.

https://doi.org/10.1016/S1161-0301(02)00107-7

Kumagai, E., \& Sameshima, R. (2014). Genotypic Differences in Soybean Yield Responses to Increasing Temperature in a Cool Climate Are Related to Maturity Group. Agricultural and Forest Meteorology, 198-199, 265-272.

https://doi.org/10.1016/j.agrformet.2014.08.016 
Lal, M., Singh, K., Srinivasan, G., Rathore, L., Naidu, D., \& Tripathi, C. (1999). Growth and Yield Responses of Soybean in Madhya Pradesh, India to Climate Variability and Change. Agricultural and Forest Meteorology, 93, 53-70. https://doi.org/10.1016/S0168-1923(98)00105-1

Liu, H. L., Yang, J. Y., Drury, C. F., Reynolds, W. D., Tan, C. S., Bai, Y. L., Hoogenboom, G. et al. (2011). Using the DSSAT-CERES-Maize Model to Simulate Crop Yield and Nitrogen Cycling in Fields under Long-Term Continuous Maize Production. Nutrient Cycling in Agroecosystems, 89, 313-328. https://doi.org/10.1007/s10705-010-9396-y

Lobell, D. B., \& Ortiz-Monasterio, J. I. (2006). Evaluating Strategies for Improved Water Use in Spring Wheat with CERES. Agricultural Water Management, 84, 249-258. https://doi.org/10.1016/j.agwat.2006.02.007

Mavromatis, T., Boote, K. J., Jones, J. W., Irmak, A., Shinde, D., \& Hoogenboom, G. (2001). Developing Genetic Coefficients for Crop Simulation Models with Data from Crop Performance Trials. Crop Science, 41, 40-51. https://doi.org/10.2135/cropsci2001.41140x

McQuigg, J. D., Thompson, L., Duc, S., Lockard, M., \& McKay, G. (1973). The Influence of Weather and Climate on United States Grain Yields: Bumper Crops or Drought. Rep. to the Associate Administrator for Environmental Monitoring and Prediction, NOAA, US Dep. Commerce.

Mera, R. J., Niyogi, D., Buol, G. S., Wilkerson, G. G., \& Semazzi, F. H. M. (2006). Potential Individual versus Simultaneous Climate Change Effects on Soybean (C3) and Maize (C4) Crops: An Agrotechnology Model Based Study. Global and Planetary Change, 54, 163-182. https://doi.org/10.1016/j.gloplacha.2005.11.003

Osborne, T. M., \& Wheeler, T. R. (2013). Evidence for a Climate Signal in Trends of Global Crop Yield Variability over the Past 50 Years. Environmental Research Letters, 8, Article ID: 024001. https://doi.org/10.1088/1748-9326/8/2/024001

Ratliff, L. F., Ritchie, J. T., \& Cassel, D. K. (1983). A Survey of Field-Measured Limits of Soil Water Availability and Related Laboratory Measured Properties. Soil Science Society of America Journal, 47, 770-775. https://doi.org/10.2136/sssaj1983.03615995004700040032x

Res, C., Brassard, J. P., \& Singh, B. (2007). Effects of Climate Change and $\mathrm{CO}_{2}$ Increase on Potential Agricultural Production in Southern Québec. Climate Change, 34, 105-117. https://doi.org/10.3354/cr034105

Romero, C. C., Hoogenboom, G., Baigorria, G. A., Koo, J., Gijsman, A. J., \& Wood, S. (2012). Reanalysis of a Global Soil Database for Crop and Environmental Modeling. Environmental Modelling \& Software, 35, 163-170. https://doi.org/10.1016/j.envsoft.2012.02.018

Setiyono, T. D., Weiss, A., Specht, J., Bastidas, A. M., Cassman, K. G., \& Dobermann, A. (2007). Understanding and Modeling the Effect of Temperature and Day-Length on Soybean Phenology under High-Yield Conditions. Field Crops Research, 100, 257-271. https://doi.org/10.1016/j.fcr.2006.07.011

Southworth, J., Pfeifer, R. A., Habeck, M., Randolph, J. C., Doering, O. C., Johnston, J. J., \& Rao, D. G. (2002). Changes in Soybean Yields in the Midwestern United States as a Result of Future Changes in Climate, Climate Variability, and $\mathrm{CO}_{2}$ Fertilization. Climatic Change, 53, 447-475. https://doi.org/10.1023/A:1015266425630

Southworth, J., Randolph, J. C., Habeck, M., Doering, O. C., Pfeifer, R. A., Rao, D. G., \& Johnston, J. J. (2000). Consequences of Future Climate Change and Changing Climate Variability on Maize Yields in the Midwestern United States. Agriculture, Ecosystems \& Environment, 82, 139-158. https://doi.org/10.1016/S0167-8809(00)00223-1 
Thuzar, M., Puteh, A. B., Abdullah, N. A. P., Lassim, M. B. M., \& Jusoff, K. (2010). The Effects of Temperature Stress on the Quality and Yield of Soya Bean [( Glycine max L.) Merrill.]. Journal of Agricultural Science, 2, 172-179. https://doi.org/10.5539/jas.v2n1p172

Tsuji, G. Y., Hoogenboom, G., \& Thornton, P. K. (1998). Understanding Options for Agricultural Production. Berlin: Springer. https://doi.org/10.1007/978-94-017-3624-4

Tsuji, G. Y., Uehara, G., \& Balas, S. (1994). DSSAT Version 3. User's Guide. Int. Benchmark Sites Network for Agrotechnol. Transfer, Dep. of Agron. and Soil Sci., College of Trop. Agric. and Human Resour., Univ. of Hawaii, Honolulu.

Tubiello, F., Rosenzweig, C., Goldberg, R., Jagtap, S., \& Jones, J. (2002). Effects of Climate Change on US Crop Production: Simulation Results Using Two Different GCM Scenarios. Part I: Wheat, Potato, Maize, and Citrus. Climate Research, 20, 259-270. https://doi.org/10.3354/cr020259

United States Department of Agriculture National Agricultural Statistics Service (USDANASS) (2015). Quickstats Alabama.

Wang, F., Fraisse, C. W., Kitchen, N. R., \& Sudduth, K. A. (2003). Site-Specific Evaluation of the CROPGRO-Soybean Model on Missouri Claypan Soils. Agricultural Systems, 76, 985-1005. https://doi.org/10.1016/S0308-521X(02)00029-X

Wang, M., Li, Y., Ye, W., Bornman, J., \& Yan, X. (2011). Effects of Climate Change on Maize Production, and Potential Adaptation Measures: A Case Study in Jilin Province, China. Climate Research, 46, 223-242. https://doi.org/10.3354/cr00986

Watanabe, M., Suzuki, T., O’Ishi, R., Komuro, Y., Watanabe, S., Emori, S., Kimoto, M. et al. (2010). Improved Climate Simulation by MIROC5: Mean States, Variability, and Climate Sensitivity. Journal of Climate, 23, 6312-6335.

https://doi.org/10.1175/2010JCLI3679.1 